\title{
Research on Rolling Motion Mode of a Catamaran unmanned craft with Monitoring Function
}

\author{
Yu Yongqiang, Yang Songlin, Li Yang, Liu Man, Tan Xiaoping
}

\begin{abstract}
In this paper, a watershed monitoring catamaran unmanned craft was taken as the research object, and a series of roll free attenuation tests was carried out with different drafts and different inception tilt angles of the craft, and a series of roll angular velocity curves was obtained. A mathematical model of 4 kinds of roll motion was established respectively, based on system identification theory and various modern optimization algorithms, calculation software was designed and compiled. By comparing the calculation results of the four mathematical models under different draft, the most suitable mathematical model was determined. According to the roll data of one of typical angles, the influence of the craft draft on the hydrodynamic derivative and the recovery torque coefficient was discussed. The identification results of the nonlinear motion pattern of the unmanned dual body monitoring craft were analyzed.
\end{abstract}

Index Terms - Catamaran unmanned craft; Rolling motion mode; System identification; Optimization algorithm.

\section{INTRODUCTION}

Rolling motion is an important factor causing ship rolling and even capsizing, and rolling motion has an important impact on the normal operation of the water monitoring craft. At present, most of the monitoring craft is mono-hull crafts, which have lower stability, poor seaworthiness and relatively low speed, and are not conducive to the normal and effective work of the monitoring crafts; moreover, waters monitoring crafts have the advantage of large deck space and more convenient for the layout of functional equipment.

Due to the complexity of hydrodynamic analysis of catamaran rolling and the interaction between the two hulls, the research on rolling motion mode is still a hot topic at home and abroad. Foreign scholars Y Kawahara and others have deduced a simple formula of ship roll damping based on the systematic change of hull form ${ }^{[12]}$.

The seakeeping performance of catamaran and trimaran have been studied by Shanghai Jiaotong University, Jiangsu University of Science and Technology and Naval Engineering University. It involves the use of linear and nonlinear equations and other series of methods to predict the rolling motion of multi-hull ships. Nevertheless, most scholars have carried out linear and nonlinear analysis of rolling motion, and there is little theoretical research on system identification model.

In summary, the catamaran is used as the parent ship to monitor the rolling motion of catamaran, and the research work on the rolling motion of the catamaran is introduced. According to the principle of dynamic balance in rolling motion, a mathematical model for system identification of

Yu Yongqiang, Yang Songlin, Li Yang, Liu Man, Tan Xiaoping, School of Naval Architecture \& Ocean Engineering , Jiangsu University of Science and Technology, Zhenjiang, Jiangsu, China rolling motion mode was established. The system identification program of catamaran rolling motion model based on optimization algorithm principle was compiled with C\# language. Then the experimental data of free rolling attenuation under different inception rolling angles and draft conditions were analyzed. The test results reveal that the prediction results of this ship's rolling motion are satisfactory.

\section{THE TEST MODEL AND EXPERIMENTAL SCHEME}

\section{A. Model introduction}

Taking a slender old frigate as the mother ship, the stern was changed to square stern, which was beneficial to the arrangement of solar panels and steering gear room, and the width of the ship was increased to meet the buoyancy distribution requirements. On this basis, the monitoring catamaran unmanned craft was designed, and the comprehensive optimization processing was carried out, and the model of the craft have been made. The principal dimension is shown in table 2.1.

Table 2.1 Optimization results of main dimensions of a catamaran

\begin{tabular}{|c|c|c|c|c|}
\hline $\begin{array}{l}\text { Numb } \\
\text { er }\end{array}$ & Design variable & $\begin{array}{l}\text { Symbo } \\
1\end{array}$ & Value & Unit \\
\hline 1 & Length & $L$ & 1.472 & $\mathrm{~m}$ \\
\hline 2 & Demihull width & $B$ & 0.13 & $\mathrm{~m}$ \\
\hline 3 & Demihull spacing & C & 0.26 & $\mathrm{~m}$ \\
\hline 4 & Depth & $D$ & $\begin{array}{l}0.078 \\
8\end{array}$ & $\mathrm{~m}$ \\
\hline 5 & Draft & d & $\begin{array}{l}0.046 \\
3\end{array}$ & $\mathrm{~m}$ \\
\hline 6 & Block coefficient & $C_{b}$ & 0.552 & \\
\hline 7 & $\begin{array}{l}\text { Waterplane } \\
\text { coefficient }\end{array}$ & $C_{w}$ & 0.770 & \\
\hline 8 & $\begin{array}{l}\text { Midship section } \\
\text { coefficient }\end{array}$ & $C_{m}$ & 0.889 & \\
\hline 9 & Velocity & $V$ & 5 & $\mathrm{kn}$ \\
\hline 10 & Displacement & $\Delta$ & 10 & $\mathrm{~kg}$ \\
\hline
\end{tabular}

The single-body lines plan of the craft model and the catamaran craft are shown in
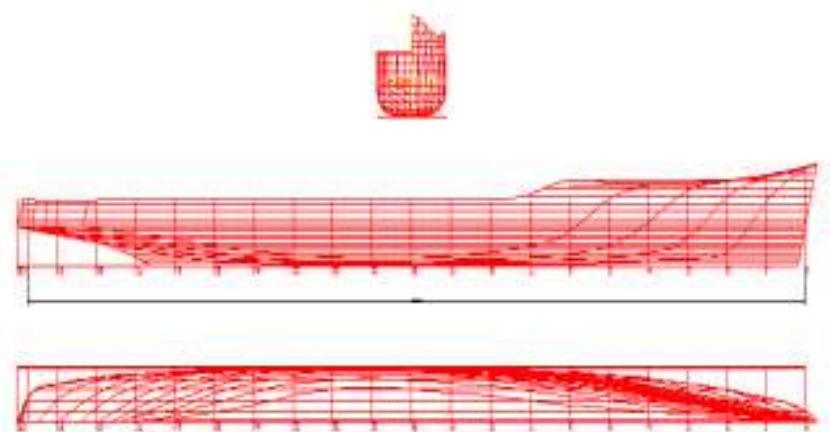


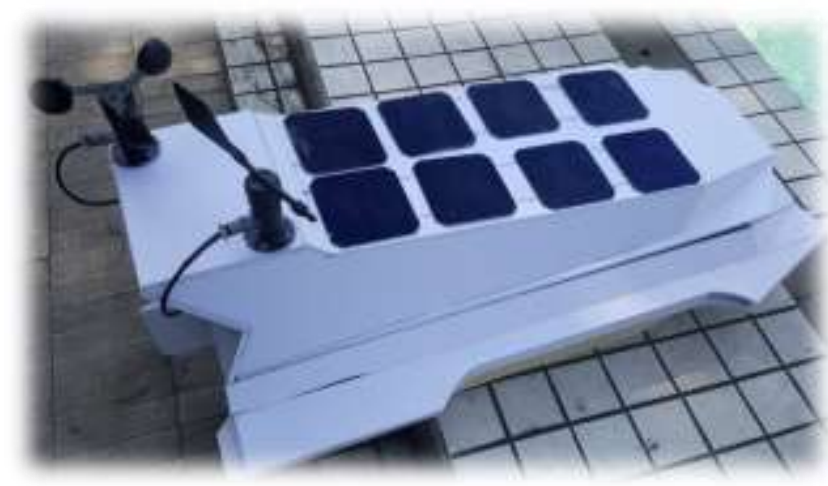

Fig2.1. molded lines and real ship

\section{B. The experimental equipment}

MTi-G is a micro inertial measurement system integrated with GPS signals. It can output three-axis acceleration, angular velocity, three axis attitude angle (pitch/roll/yaw angle). Built-in high-precision anti-vibration gyroscope chip $\left(10^{\circ} / \mathrm{h}\right)$, it can be in vibration environment, non-uniform magnetic field environment, high-precision output three-axis gesture angle.

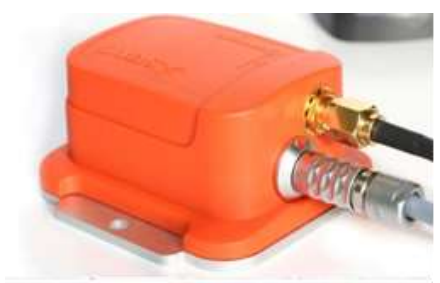

Fig.2.2 MTi-G

Mti-G was placed at the center of gravity of the model of craft. After the model of craft was launched, the model of craft was positively floated by adjusting the ballast. The model was given an inception roll angle, and then freely swayed. The data measured by Mti was transmitted and saved to the computer on shore.

\section{Methods of procedure}

In order to obtain the best roll free attenuation data, the transverse direction of the model of the catamaran was perpendicular to the long side of the pool during the experiment. At the same time, in order to reduce the effect of the wall of the tank on the rolling motion of the catamaran model, wave attenuation devices were placed at both ends of the tank to absorb the waves generated during the rolling process.

In order to investigate the variation of rolling free attenuation at different angles, three kinds of rolling tests under different draft conditions, namely, 0.9 times, 1.1 times and standard, were carried out according to the shallow draft characteristics of the catamaran model. In order to better reflect the stability of the data, we have carried out nine groups of roll tests at $2^{\circ}, 6^{\circ}$ and $10^{\circ}$ degrees respectively.

In the sensor MTi-G was fixed at the center of the catamaran model with double faced adhesive tape, and the part of the sensor connected with the computer was transmission by flexible data cable. In the experiment, the model was compressed to inception rolling angle by the staff at the rear of the catamaran model, and the measurement was carried out quickly. Considering the influence of the errors produced in the process of experiment operation, each angle was measured three times, and the best set of data was selected at last. The table of rolling experiments at different angles and under draught are shown below.

Table 2.2 Rolling test record form ( $\sqrt{ }:$ Description of the experiment,$\times$ : Description did not experiment )

\begin{tabular}{lllllll}
\hline $\begin{array}{l}\text { Rolling } \\
\text { angle }\end{array}$ & $2^{\circ}$ & $4^{\circ}$ & $5^{\circ}$ & $6^{\circ}$ & $8^{\circ}$ & $10^{\circ}$ \\
\hline 0.9 times & $\sqrt{ } \times$ & & $\times$ & $\sqrt{ }$ & $\times$ & $\sqrt{ }$ \\
draft & & & & & \\
$\begin{array}{l}\text { standard } \\
\text { draft }\end{array}$ & $\sqrt{ } \times$ & $\times$ & $\sqrt{ }$ & $\times$ & $\sqrt{ }$ \\
$\begin{array}{l}1.1 \text { times } \\
\text { draft }\end{array}$ & $\sqrt{ } \times$ & $\times$ & $\sqrt{ }$ & $\times$ & $\sqrt{ }$ \\
\hline
\end{tabular}

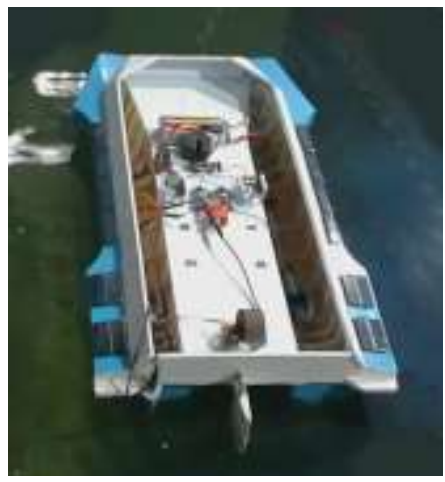

Fig.2.2 Hydrostatic roll attenuation test for catamaran unmanned craft in still area

\section{SYSTEM IDENTIFICATION EQUATION AND MODEL}

Identification is the process of data processing and mathematical calculation to determine a model which is "equivalent" to the characteristics of the system. In this paper, we use the genetic algorithm as the core, and use the $\mathrm{C \#}$ language to compile the system identification program.

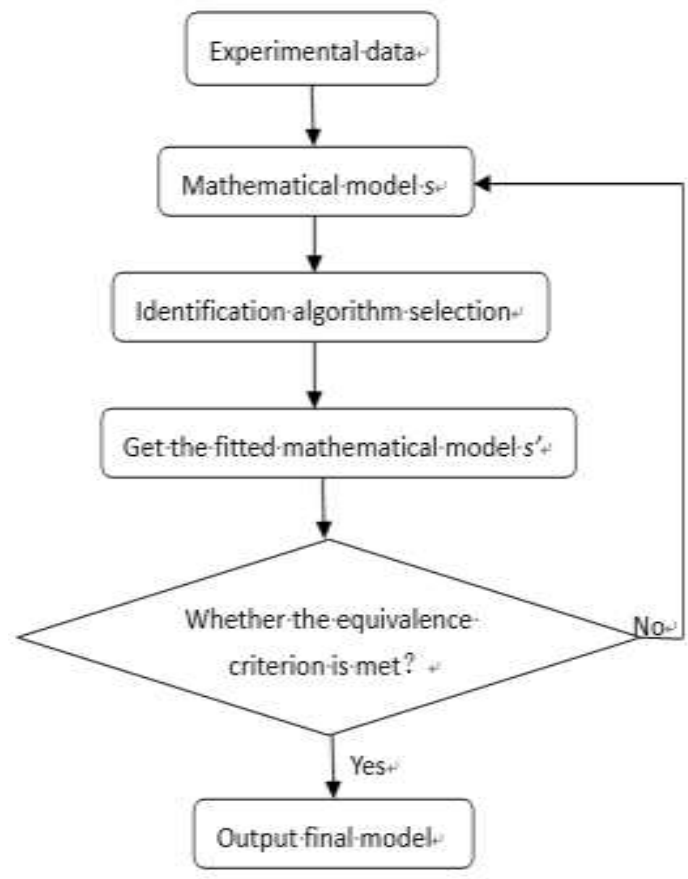

Fig.3 System identification flow chart 


\section{A. Identification mathematical model}

According to the force analysis of rolling motion, the balance equation of motion can be obtained. According to the balance principle, the sum of the forces acting on the hull at any time to the $\mathrm{x}$-axis torque is zero, which is the following balance equation:

$$
M(\ddot{\varphi})+M(\dot{\varphi})+M(\varphi)=0
$$

In this paper, four identification equations were introduced, which mainly modified the terms of roll recovery torque, and used linear and nonlinear equations respectively to represent recovery torque. The equations are as follows:

Equation 1 :

$$
\begin{aligned}
& \ddot{\varphi}+2 \frac{\lambda}{I_{\mathrm{x}}} \dot{\varphi}+2 \frac{\alpha}{I_{\mathrm{x}}}|\dot{\varphi}| \dot{\varphi}+\frac{x}{I_{\mathrm{x}}} \dot{\varphi}^{3} \\
& +\frac{a}{I_{\mathrm{x}}} \varphi^{3}+\frac{b}{I_{\mathrm{x}}} \varphi^{2}+\frac{c}{I_{\mathrm{x}}} \varphi=0
\end{aligned}
$$

Equation 2 :

$$
\begin{aligned}
& \stackrel{\bullet}{\varphi}+2 \frac{\lambda}{I_{\mathrm{x}}} \dot{\varphi}+2 \frac{\alpha}{I_{\mathrm{x}}}|\dot{\varphi}| \dot{\varphi}+\frac{x}{I_{\mathrm{x}}} \dot{\varphi}^{3} \\
& +\frac{\Delta h}{I_{\mathrm{x}}} \sin \varphi=0
\end{aligned}
$$

Equation 3 :

$$
\begin{aligned}
& \ddot{\varphi}+2 \frac{\lambda}{I_{\mathrm{x}}} \dot{\varphi}+2 \frac{\alpha}{I_{\mathrm{x}}}|\dot{\varphi}| \dot{\varphi}+\frac{x}{I_{\mathrm{x}}} \dot{\varphi}^{3}+ \\
& \frac{a}{I_{\mathrm{x}}}(\sin \varphi)^{3}+\frac{b}{I_{\mathrm{x}}}(\sin \varphi)^{2}+\frac{c}{I_{\mathrm{x}}} \sin \varphi=0
\end{aligned}
$$

Equation 4 :

$$
\begin{aligned}
& \stackrel{\bullet}{\varphi}+2 \frac{\lambda}{I_{\mathrm{x}}} \dot{\varphi}+2 \frac{\alpha}{I_{\mathrm{x}}}|\dot{\varphi}| \dot{\varphi}+\frac{x}{I_{\mathrm{x}}} \dot{\varphi}^{3}+ \\
& \frac{c d}{I_{\mathrm{x}}} \sin \varphi+\frac{e}{I_{\mathrm{x}}} \varphi=0
\end{aligned}
$$

Which is:

$I_{X}$ _total inertia torque; $\phi$ _roll angle; $\dot{\phi}$ _roll angular velocity; $\ddot{\phi}$ _roll angular acceleration; $\lambda$-linear damping torque coefficient of rolling; $\alpha$ - $\mathrm{x}$-nonlinear damping torque coefficient of rolling; $\mathrm{h}$ - high inception stability; a-cubic recovery torque coefficient ; b-quadratic recovery torque coefficient ; $\mathrm{c} 、 \mathrm{~d} 、 \mathrm{e}$-linear recovery torque coefficient.

By measuring the angle of the test $\mathrm{K}$, the error estimation criteria at $\mathrm{K}+1$ time are as follows:

$$
\varepsilon_{k+1}=\dot{\phi}_{k+1}^{\prime}-\dot{\phi}_{k+1}
$$

Which is:
$\dot{\phi}_{K+1}$ is the measured value of the angular velocity of $\mathrm{K}+1$ time; $\dot{\phi}_{K+1}^{\prime}$ is the value obtained by the angular velocity identification of $\mathrm{K}+1$ times.

Then the objective function was selected as shown in equation 2.7. The smaller the objective function value is, the better the formula imitative effect is.

$$
F(x)=\sqrt{1 / N \sum_{k=1}^{N}\left(\dot{\phi}_{K+1}^{\prime}-\dot{\phi}_{K+1}\right)^{2}}
$$

The three design variables of $\phi, \dot{\phi}$ and $\ddot{\phi}$ in the above formula can be directly measured from the test. Using the micro-element method, the sensor measures a set of data every 0.01 seconds during the test, and then finds other parameters required by linear fitting, and at the same time determines the linearity of the roll and the nonlinear recovery torque coefficient and damping torque coefficient. The range of design variables is shown in table 2.2.1.

Table 2.2.1 Range of Design Variables

\begin{tabular}{ll}
\hline Project & Ranges \\
\hline Total moment of inertia $I x$ & $0 \sim 0.1$ \\
Rolling linear damping moment coefficient $\lambda_{\theta}$ & $0 \sim 1$ \\
Rolling nonlinear damping moment coefficient $\alpha$ & $0 \sim 1$ \\
Rolling nonlinear damping moment coefficient $x$ & $0 \sim 10$ \\
Cubic recovery moment coefficient $a$ & $0 \sim 10$ \\
Quadratic recovery moment coefficient $b$ & $0 \sim 10$ \\
Linear recovery moment coefficient $c$ & $0 \sim 10$ \\
\hline
\end{tabular}

\section{ROLLING MOTION, MATHEMATICAL MODEL} AND SYSTEM IDENTIFICATION METHOD OF CATAMARAN CRAFT

\section{A. Analyses of the results of the roll test}

The hydrostatic monitoring of the two-body unmanned watercraft in the water area was completed. During the test, e ch inception roll angle was tested three times, and the best set of test data was selected as the effective data. Due to the human factors, there is a certain error in the test. Figure 3.1 shows the inception roll angle of $6^{\circ}$, the draft is 0.9 times the design draft, the design draft, and the 1.1 times the design draft. The roll angular velocity decay is compounded in the figure, so the test data of roll is available.

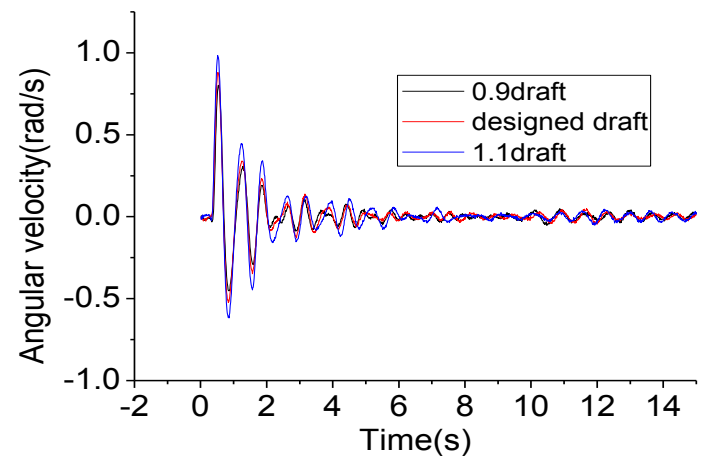

Fig3.1 Rolling angular velocity decay curve under different draft and rolling inception angle of $6^{\circ}$ 
As shown in Figure 3.1, when the three kinds of draft and the inception roll angle are $6^{\circ}$. With the increase of draught, the peak value of rolling angular velocity increases, the rolling period decreases; and tends to be stable around 8 s, and there is a small fluctuation after 10 s, which may be influenced by other uncertain factors.

\section{B Rolling identification calculation scheme}

Design: Identification optimization algorithm selection improved genetic algorithm

Comparing the three working conditions of 0.9 times design draft, design draft and 1.1 times draft, four rolling identification models were used to identify the above three draughts. According to the size of the objective function, the most suitable free identification model for the catamaran was selected. The target functions of the four identification models were used to identify the three draft and rolling angles. The result is shown in Figure 2.2:

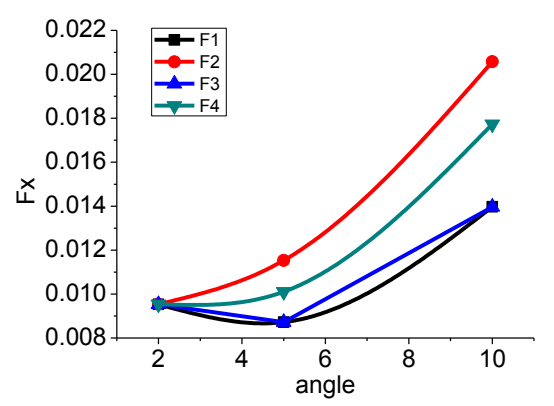

(a) 0.9 times design draft

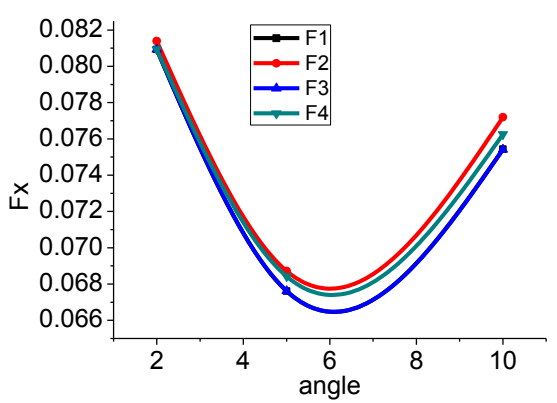

(b) Design draft

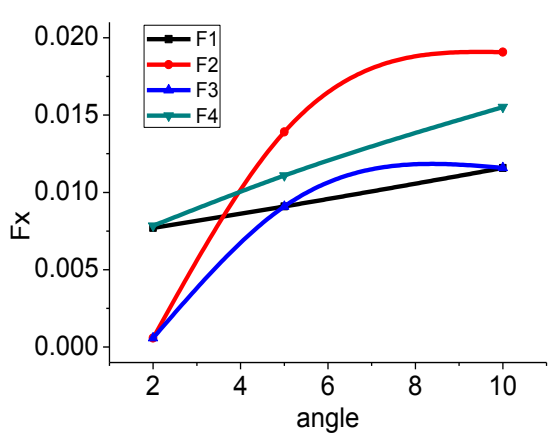

(c) 1.1 times design draft

Fig3.2 Calculation results of four identification formulas und er three different drafts conditions

In the figure, F1, F2, F3, and F4 represent the objective function 1 , the objective function 2 , the objective function 3 , and the objective function 4. It can be seen from figure.3.2 that under the three kinds of draughts, the value of the objective function 3 of the identification calculation was the smallest, indicating that the equation 3 has the best fitting effect. Taking the design draft and the inception roll angle of $6^{\circ}$ as an example, the target function value after identification is 0.008722 . The values of each design variable are shown in Table 3.3:

Table 3.3 Equation 3 identifies the optimal values of each design variable

Design variables Optimization values

\begin{tabular}{lll}
\hline $\begin{array}{l}\text { Total moment of inertia } I x \\
\text { Rolling linear damping moment }\end{array}$ & 0.014056272 \\
$\begin{array}{l}\text { coefficient } \lambda \\
\text { Rolling nonlinear } \\
\text { moment coefficient } \alpha\end{array}$ & damping & 0.008001416 \\
$\begin{array}{l}\text { Rolling nonlinear } \\
\text { moment coefficient } x\end{array}$ & damping & 0.00018325 \\
$\begin{array}{l}\text { Cubic recovery } \\
\text { coefficient } a\end{array}$ & moment & 1.068927706 \\
$\begin{array}{l}\text { Quadratic recovery } \\
\text { coefficient } b\end{array}$ & moment & 8.439408682 \\
$\begin{array}{l}\text { Linear recovery } \\
\text { coefficient } c\end{array}$ & moment & 0.974562376
\end{tabular}

The rolling motion model is as follows:

$\ddot{\phi}+1.13845 \dot{\phi}+0.01304|\dot{\phi}| \dot{\phi}+0.11091 \dot{\phi}^{3}+76.04781(\sin \phi)^{3}$

$+600.41328(\sin \phi)^{2}+69.33423 \sin \phi=0$

In order to analyze the error between the experimental value and the fitted value, the angular velocity test value of the design draught and the inception roll angle of $6^{\circ}$ and the fitted value identified by Equation 3 are placed in the same coordinate system, as shown in Figure 3.3 :

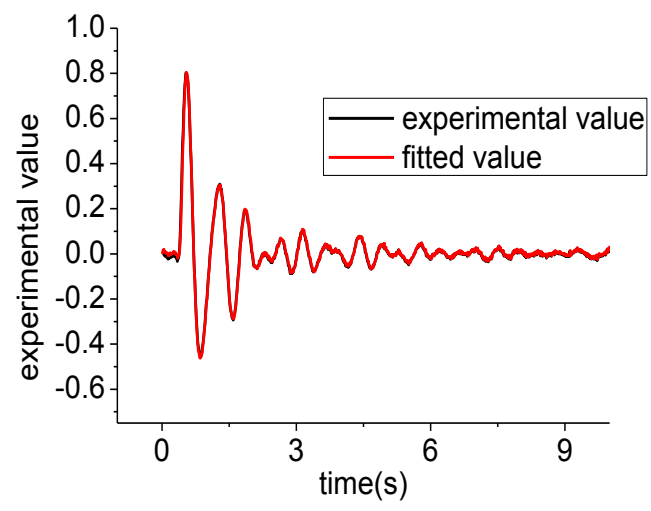

Fig3.3 Test angular velocity and identification angular velocity fitting curve

It can be seen from the above figure that the experimental angular velocity and the identification angular velocity have good imitative effects, which can prove the reliability and stability of the equation 3 in the identification software model. 
The total inertia torque Ix, damping torque coefficient $\lambda$, square damping torque coefficient $\alpha$, cubic damping torque coefficient $\mathrm{x}$ and restoring torque coefficients under each condition obtained by identifying and calculating nine groups of rolling test data. Among them, the curves of the design variables with the inception roll angle under three kinds of draught are shown in figure 3.4-3.6.

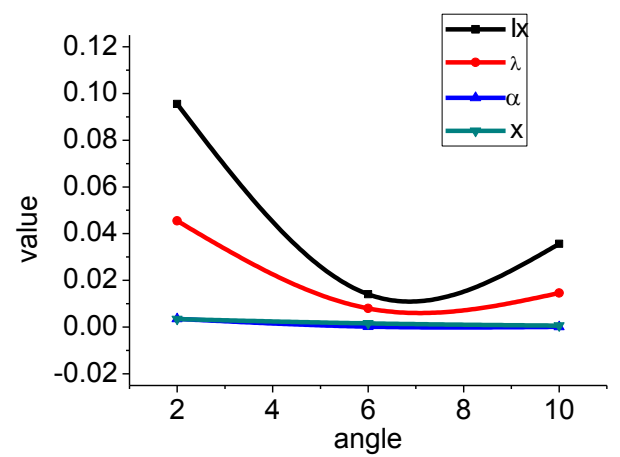

(a)

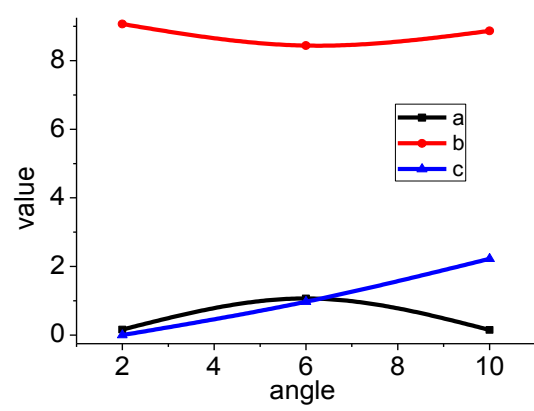

(b)

Fig3.4 Curves of torque coefficients varying with inception roll angle under 0.9 times designed draft

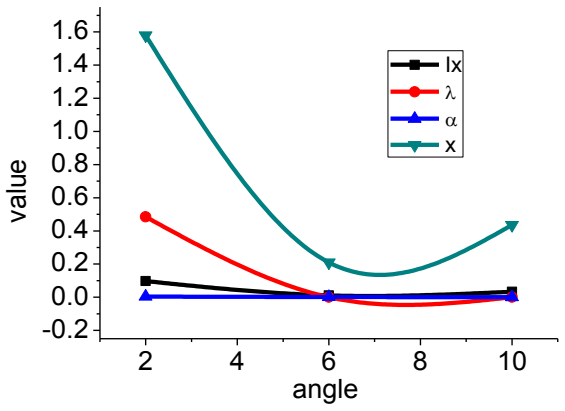

(a)

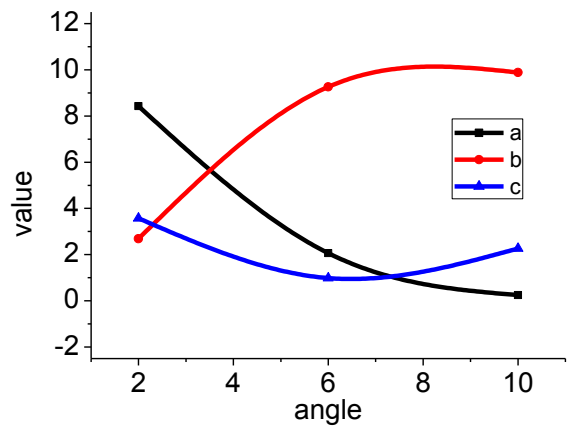

(b)

Fig3.5 Curves of torque coefficients varying with inception roll angle under designed draft

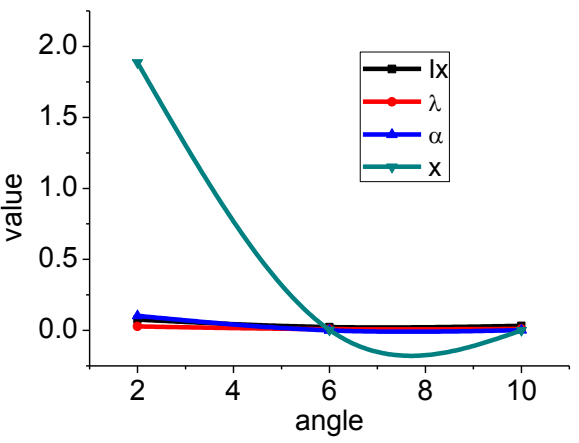

(a)

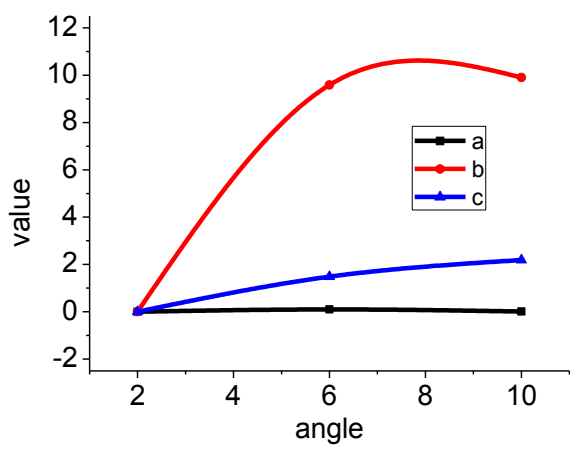

(b)

Fig3.6 Curves of torque coefficients varying with inception roll angle under 1.1 times designed draft

It can be known from Fig. 3.4-3.6, the values of the torque coefficients vary with the draught and the inception roll angle. At the same inception roll angle, the total torque of inertia was decreased with the increase of draught. When the linear damping $\lambda$ is less than $6^{\circ}$, the linear damping $\lambda$ decreases with the increase of the draught and the inception roll angle. The results show that the nonlinear damping coefficient $\alpha$ has little effect on the rolling motion of the model, and the cubic damping torque decreases first and then increases with the increase of the inception rolling angle under the design draft and 1.1 times of the design draft. When the inception rolling angle is $2^{\circ}-7^{\circ}$, the $\mathrm{x}$ decreases rapidly and the $8^{\circ}--10^{\circ}$ increases. When the inception roll angle of cubic restoring torque coefficient a is $10^{\circ}$, with the increase of draught, the coefficient of linear recovery torque is about 0 when the design draught is 1.1 times, and tends to be stable; the coefficient of quadratic recovery torque $b$ appears a relatively stable state after a relatively large increase; the coefficient of linear recovery torque is $\mathrm{c}$ when the design draught is 0.9 times and the design draught is 1.1 times. As the inception roll angle increases, it increases.

\section{IN CONCLUSION}

In this paper, the model test and system identification method are used to study the hydrostatic roll attenuation motion mode of the catamaran unmanned craft in the water area. The static water roll mathematical model and the torque coefficient of the craft model under 9 working conditions are obtained by the identification program. The variation law of different draught with rolling angle :

1). When the design draught was 0.9 , the hull rolling total torque of inertia Ix and the quadratic restoring torque coefficient $b$ have a great influence on the rolling mode of the catamaran; 
2). When designing the draft and 1.1 times the design draft, the cubic damping $\mathrm{x}$ and the restoring torque coefficient $\mathrm{b}$ have a major influence on the rolling mode of the catamaran; 3 ). When the roll angle is $2^{\circ}$, the cube of hull roll damping torque coefficient increases as $\mathrm{x}$ increases draft;

4). When the roll angle is $10^{\circ}$, any draught, and the quadratic restoring torque coefficient $b$ and the linear restoring torque coefficient $\mathrm{c}$ have a great influence on the rolling mode of the catamaran.

In this paper, the correctness and stability of the system identification software was verified. The system identification software can predict the future navigation parameters and motion mode of unmanned craft, which can provide the reference for further study of other swaying motion of catamaran.

Acknowledgement :

This project is funded by the following projects: The Nation al Natural Science Foundation of China, the project approval number is 51379094 .

\section{REFRENCE}

[1] Li Peiyong, Feng Tiecheng, Pei Yongming. Three-hull Ship Rolling Motion [J]. Shipbuilding of China, 2003, 44(1): 24-30.

[2] Yao Di, Lu Xiaoping, Wang Yi. Trial Ship Rolling Model Test and It Characteristic Analysis [J]. Chinese Journal of Ship Research, 2010, 05(4): 6-11.

[3] Liu Sheng, Yang Zhen. Real-time online forecasting method for ship rolling motion [J]. Electric Machines and Control, 2011, 15(10): 82-87.

[4] Liu Fuwei, Xu Haitong, Yang Songlin. Preliminary Study on Rolling Characteristics of a Type of Amphibious Unmanned Concept craft [J] Chinese Journal of Ship Research, 2014, 9(1): 46-51.

[5] Xia Zhiping, Wen Yiyan, Yang Songlin, et al. Analysis of the rolling motion mode of a new trimaran [J]. Ship Science and Technology, 2014, 36(2): 33-36.

[6] LI Haixia. Research on Mathematical Modeling of Time Series Prediction of Ship Rolling Motion under Wave Influence [J]. Ship Science and Technology, 2017(22):13-15.

[7] Ding Feng. System Identification (1): Identification Guidance [J]. Journal of Nanjing University of Information Technology, 2011, 03(1):1-22

[8] Sun Xiaoshuai, Yao Chaobang, Ye Qing. Numerical and Experimental Study on Rolling Damping Characteristics of Small Waterplane Catamaran [J]. Journal of National University of Defense Technology, 2017(6).

[9] Zhang Yulong, Li Hongxia, Wang Wenhua, Zhen Xingwei. Research on Determination Method of Ship Rolling Damping [J].China Shipbuilding, 2015, 56(S1):155-160.

[10] Liu S, Papanikolaou A. Prediction of parametric rolling of ships in single frequency regular and triple frequency group waves [J]. Ocean Engineering, 2016, 120:274-280.

[11] Jovanoski Z, Robinson G. Ship Stability and Parametric Rolling [J]. Australasian Journal of Engineering Education, 2009, 15(2):43-50.

[12] Kawahara Y, Maekawa K, Ikeda Y. A Simple Prediction Formula of Roll Damping of Conventional Cargo Ships on the Basis of Ikeda's Method and Its Limitation[M]// Contemporary Ideas on Ship Stability and Capsizing in Waves. Springer Netherlands, 2011:201-210. 